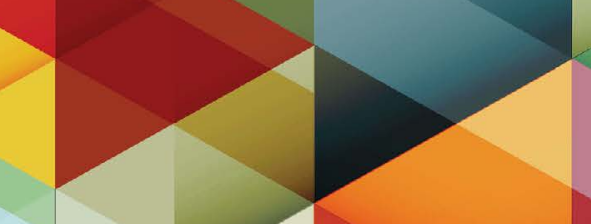

\title{
A ASSISTÊNCIA ESTUDANTIL E O ACESSO DOS JOVENS DA REGIÃO DO SERTÃO DE CRATEÚS AO ENSINO SUPERIOR: UM ESTUDO COM ALUNOS DO IFCE
}

\author{
STUDENT ASSISTANCE AND ACCESS OF YOUNG PEOPLE FROM THE \\ CRATEÚS DRY BACKLAND REGION TO HIGHER EDUCATION: \\ A STUDY WITH STUDENTS FROM IFCE
}

\section{LA ASISTENCIA ESTUDIANTIL Y EL ACCESO DE LOS JÓVENES DE LA REGIÓN DEL SERTÓN DE CRATEÚS A LA ENSEÑANZA SUPERIOR: UN ESTUDIO CON ALUMNOS DEL IFCE}

\section{Mônica Duarte Cavaignac* \\ Edna Mota Loiola**}

*Professora adjunta da Universidade Estadual do Ceará (UECE), vinculada ao curso de Serviço Social e ao Mestrado Acadêmico em Serviço Social, Trabalho e Questão Social. Líder do Grupo de Estudos e Pesquisas em Políticas Públicas e Exclusão Social (GEPPES/UECE) e membro do Observatório Juventude, Educação Profissional e Trabalho (UECE). Graduada em Serviço Social pela UECE e em Direito pelo Centro Universitário Estácio de Sá Mestre em Educação e Doutora em Sociologia pela Universidade Federal do Ceará (UFC). Fortaleza, Ceará, Brasil. E-mail: monica.cavaignac@uece.br

**Pesquisadora do Laboratório e Grupo de Estudos e Pesquisas em Políticas Públicas e Exclusão Social (GEPPES) da UECE. Graduada em Serviço Social pela UECE. Fortaleza, Ceará, Brasil. E-mail: ednnamotta@hotmail.com Recebido para publicação em: 24.7.2017

Aprovado em: 11.4.2018

\section{Resumo}

Estudo realizado com jovens estudantes de nível superior usuários da assistência estudantil desenvolvida no campus do Instituto Federal em Crateús, nos Sertões do Ceará. Além de pesquisa bibliográfica e documental, envolveu pesquisa de campo, com realização de entrevistas visando compreender os significados que esses jovens atribuem à educação superior e à assistência estudantil, bem como a importância desta última em sua trajetória acadêmica e de vida. A pesquisa revela que o desenvolvimento do programa de assistência estudantil é um mecanismo que propicia o acesso ao ensino superior, entendido em perspectiva ampla, que compreende, além do ingresso, a garantia aos estudantes, sobretudo àqueles pertencentes às camadas mais pobres, de condições de permanência nos cursos, favorecendo a qualidade da formação profissional.

Palavras-chave: Ensino superior. Juventude. Acesso. Assistência estudantil.

\section{Abstract}

This study was carried out with young students of higher education, benefited from the student assistance developed in the campus of the Federal Institute in Crateús, in the Ceará backlands. In addition to bibliographical and documentary research, it involved field research, with interviews aimed at understanding which meanings these young people attribute to higher education 
and student assistance. The research reveals that student assistance provides access to higher education, understood in a broad perspective, which includes, in addition to admission, the guarantee to students, especially those belonging to the poorer classes, of conditions for permanence in the courses, favoring the quality of professional qualification.

Keywords: Higher education. Youth. Access. Student assistance.

\section{Resumen}

Estudio realizado con jóvenes estudiantes de nivel superior usuarios de la asistencia estudiantil desarrollada en el campus del Instituto Federal en Crateús, en los Sertones de Ceará. Además de la investigación bibliográfica y documental, este estudio involucró investigación de campo, entrevistas para comprender los significados que estos jóvenes atribuyen a la educación superior y a la asistencia estudiantil. La investigación revela que la asistencia estudiantil propicia el acceso a la enseñanza superior, entendido en perspectiva amplia, que comprende, además del ingreso, la garantía a los estudiantes, sobre todo a aquellos pertenecientes a las capas más pobres, de condiciones de permanencia en los cursos, favoreciendo la calidad de la formación profesional.

Palabras clave: Enseñanza superior. Juventud. Acceso. Asistencia estudiantil.

\section{Introdução}

A educação, como direito de todos e dever do Estado e da família, está garantida no artigo 205 da Constituição Federal de 1988, que estabelece como um dos princípios do ensino a igualdade de condições para o acesso e a permanência na escola (BRASIL, 2012, art. 206), o que também está previsto no artigo $3^{\circ}$ da Lei de Diretrizes e Bases da Educação Nacional (LDBEN), Lei n. 9.394/1996. Todavia, para que o direito universal à educação se efetive no Brasil, são necessárias políticas que garantam condições de acesso e de permanência dos estudantes nas instituições públicas de ensino.

De acordo com Kowalski (2012), no que se refere ao ensino superior, a situação brasileira quanto aos percentuais de inclusão dos jovens em idade universitária é desfavorável quando comparada à de outros países da América Latina, como Argentina (40\%), Chile (35,9\%), Venezuela (26\%) e Bolívia (20,6\%). Mesmo com a ampliação da oferta de ensino público, a criação de novos estabelecimentos de ensino e o aumento do número de matrículas na última década, em 2012, apenas 15\% da população com idade entre 18 e 24 anos estava matriculada em cursos superiores, conforme relata a Associação Nacional dos Dirigentes de Instituições Federais de Ensino Superior (2012).

O sistema de ensino superior brasileiro é constituído por universidades, faculdades, institutos superiores e centros de educação tecnológica, sendo que cerca de 
301 destas instituições de ensino superior (IES) são públicas e 2.090 são privadas; nestas últimas estudam cerca de $71 \%$ dos jovens universitários brasileiros (ASSOCIAÇÃO NACIONAL DOS DIRIGENTES DE INSTITUIÇÕES FEDERAIS DE ENSINO SUPERIOR, 2016). O expressivo número de IES privadas, nas quais ingressa a maior parte dos estudantes, revela o processo de transformação da educação em uma mercadoria, perdendo assim a configuração de direito social.

No cenário de expansão intensiva e acelerada do ensino superior privado, outro dado preocupante diz respeito às taxas de evasão (12\% nas IES públicas e 25\% nas privadas), cujas causas são principalmente as deficiências da formação básica, a escolha precoce da especialidade profissional, as dificuldades financeiras e as dificuldades de mobilidade estudantil (ASSOCIAÇÃO NACIONAL DOS DIRIGENTES DE INSTITUIÇÕES FEDERAIS DE ENSINO SUPERIOR, 2015).

Segundo Santos e Freitas (2014), a assistência estudantil pode constituir-se em um mecanismo de combate à evasão, tendo como finalidade atender às necessidades dos estudantes e prover os recursos necessários para que estes transponham os obstáculos financeiros e/ou de aprendizagem, que dificultam ou impedem o bom rendimento acadêmico, de modo a minimizar os percentuais de trancamento de matrículas e de abandono de cursos.

A assistência

estudantil pode

constituir-se em

um mecanismo de

combate à evasão

Nesse sentido, a assistência estudantil passa a ser fundamental para garantir a permanência dos estudantes nas IES por meio de direitos que apenas o ingresso não propicia. Afınal, os motivos da evasão são perpassados tanto por dificuldades econômicas quanto pela ausência ou insuficiência de apoio pedagógico institucional, que em determinadas situações é essencial para romper com os déficits de aprendizado trazidos do ensino médio público (MENEZES, 2012).

Com o processo de expansão da educação superior, principalmente com a interiorização dos Institutos Federais (IF), aumenta consideravelmente a demanda por assistência estudantil, a qual se torna um mecanismo que possibilita garantir condições justas de permanência no ensino superior, com o intuito de reduzir as desigualdades sociais e transformar as universidades e os institutos em espaços públicos, democráticos e construtores da cidadania.

O presente artigo, fundamentado em pesquisa bibliográfica, documental e de campo, tem por objetivo apresentar a realidade de estudantes matriculados em cursos de licenciatura e bacharelado do Instituto Federal de Educação, Ciência e Tecnologia do Ceará (IFCE) - campus Crateús ${ }^{1}$, município localizado em uma região dos Sertões, onde é crescente a oferta de diversos cursos de graduação em diferentes modalidades, o que contribui para o aumento do número de jovens, inclusive das cidades circunvizinhas, que buscam ingressar no ensino superior.

Como técnica de investigação, foi utilizada a entrevista semiestruturada, com auxílio de gravador e caderno de anotações, com a finalidade de apreender as concepções, 
os significados, os valores, os anseios e as expectativas dos jovens estudantes em relação ao ensino superior e à assistência estudantil. O critério de amostragem considerou a acessibilidade e a disponibilidade dos jovens para participar da pesquisa. Foram entrevistados alunos de todos os cursos superiores ofertados no campus, a saber: curso de bacharelado em Zootecnia, licenciatura em Matemática, licenciatura em Letras e licenciatura em Física. Para traçar o perfil socioeconômico dos jovens que são beneficiários do programa de assistência estudantil do IFCE-Crateús, realizou-se uma pesquisa documental junto à Coordenadoria de Assuntos Estudantis (CAE), a qual disponibilizou documentos que apontam dados socioeconômicos dos alunos assistidos.

\section{Ensino superior e assistência estudantil no Brasil: da década de 1930 aos dias atuais}

O ensino superior no Brasil começa a se desenvolver no século 20², em uma conjuntura marcada por transformações econômicas, ideopolíticas e socioculturais. A Constituição Federal de 1934 foi a primeira a legitimar a educação como um direito de todos e dever do poder público e da família. No início da década de 1930, tem-se a criação do Ministério da Educação e da Saúde Pública (MESP); a aprovação do Estatuto das Universidades Brasileiras, por meio do Decreto-lei n. 19.851/1931, que consolida os pressupostos da reforma universitária e estabelece o modelo universitário único; e a criação do Conselho Nacional de Educação, por meio do Decreto-lei n. 19.850/1931, que privilegia o sistema universitário (FÁVERO, 2006).

Esse período marca o início da assistência estudantil nas universidades, a partir de uma regulamentação jurídica que tem em vista a qualificação de mão de obra para atender às necessidades do mercado, afınal, com a inserção do País no mundo capitalista, a educação passa a ter papel primordial na formação dos trabalhadores (DUMARESQ, 2014). A concessão de bolsas segue o critério da meritocracia e a comprovação do "mérito" se dá mediante atestado de pobreza expedido por instituições de assistência social, além da observação do comportamento do indivíduo.

No contexto do Estado Novo (1937-1945), com o avanço das tendências centralizadoras e autoritárias consubstanciadas na Constituição Federal de 1937, o Estado deixa de ser o responsável por prover a educação, priorizando o ensino profissionalizante, direcionado para atender às demandas postas pelo processo de industrialização. Nesse período é criada a União Nacional dos Estudantes (UNE), entidade de representação estudantil que tem importante atuação em vários cenários políticos. A sede administrativa da UNE é a Casa do Estudante do Brasil, criada em 1930 para atender alunos carentes. Os membros da UNE organizam a biblioteca, o serviço de saúde, a concessão de bolsas e a distribuição de cargos empregatícios (DUMARESQ, 2014).

Com o fim do Estado Novo e a promulgação da Constituição Federal de 1946, a educação passa a ser concebida como direito de todos, competindo à União a respon- 
sabilidade de determinar as diretrizes que regem a política de educação nacional. Com relação à assistência estudantil, a referida Constituição, em seu artigo 172, estabelece que: "cada sistema de ensino terá obrigatoriedade de serviços de assistência educacional que assegure aos alunos necessitados condições de eficiência escolar" (BRASIL, 1946). No campo do ensino superior, há o aumento do número de universidades, no entanto, permanece o predomínio da formação profissional tecnicista, sem o desenvolvimento e socialização de pesquisas e criação de novos conhecimentos. Nesse período, o Estado se torna o empreendedor da qualificação da força de trabalho, principalmente juvenil, financiando atividades educacionais profissionalizantes no âmbito público e privado, para atender aos interesses do empresariado industrial. É importante ressaltar a criação, mediante o Decreto-lei n. 4.048/1942, do Sistema Nacional de Aprendizagem Industrial (Senai), um dos principais instrumentos utilizados pelo empresariado para qualificar a força de trabalho para trabalhar na indústria (IAMAMOTO; CARVALHO, 1985).

Há o aumento

do número de

universidades, no

entanto, permanece

o predomínio da

formação profissional

tecnicista
Já as décadas de 1950 e 1960 são marcadas por intensas discussões sobre o processo de democratização do ensino. As transformações socioeconômicas resultantes da urbanização e da industrialização, o aumento da concentração de renda e das desigualdades sociais e o crescimento do mercado de trabalho informal e do subemprego são aspectos que exercem importante influência nos debates sobre a situação da universidade. As disputas entre interesses públicos e privados se intensificam com a discussão e elaboração da primeira Lei de Diretrizes e Bases da Educação (LDB)3 ${ }^{3}$, que traz no seu texto a assistência estudantil como meio de garantir a permanência dos jovens na universidade. Nessa época, setores tradicionais se posicionaram contra a inserção da pesquisa nas escolas superiores, no entanto, o próprio processo de industrialização do País exigiu o desenvolvimento e a incorporação da ciência e da tecnologia de base nacional, sendo a universidade essencial nesse processo perpassado por complexas contradições ${ }^{4}$.

Fávero (2006) chama a atenção para a criação da Universidade de Brasília (UnB), em 1961, que tem importante contribuição para o processo de modernização do ensino superior; bem como para a decisiva participação do movimento estudantil, por intermédio da UNE, no processo de reforma universitária e no combate ao caráter arcaico e elitista predominante nas instituições universitárias. Entre as principais pautas desse movimento, destacam-se: a autonomia universitária, a participação dos docentes e discentes na administração institucional e a ampliação de vagas nas escolas públicas. Minto (2011) também salienta o papel central do movimento estudantil na defesa de uma universidade alinhada com as demandas concretas da sociedade brasileira, com igualdade de acesso, principalmente para as camadas populares. 
Durante a ditadura militar (1964-1984), com o avanço do capitalismo brasileiro, a educação superior passa a ser exigência do próprio capital, sendo sua expansão conduzida por duas premissas principais: por um lado, a capacitação da força de trabalho para atender às exigências do mercado; e, por outro, a difusão da ideologia burguesa. A chamada "política inclusiva" é tensionada por forças sociais com diferentes interesses, tais como os movimentos sociais, de estudantes e de professores, que lutam pelo fim do monopólio da universidade e pela democratização do ensino; e a burguesia, que reivindica a "modernização" da educação superior para atender às mudanças no mundo do trabalho e inserir o País na economia mundial. É nesse contexto que se opera a reforma universitária, uma importante reformulação na estrutura do ensino superior brasileiro.

Menezes (2012) e Minto (2011) observam que a lei da reforma universitária, Lei n. 5.540/1968, fragmenta as IES e as divide entre diferentes perspectivas, na medida em que reorganiza as IES públicas, estabelece a criação das IES privadas e promove o aumento da oferta de vagas, com o intuito de simular a democratização do ensino e desmobilizar as lutas sociais. Assim, enquanto as universidades desenvolvem atividades de ensino e pesquisa, as faculdades isoladas, sobretudo privadas, realizam apenas atividades de ensino. No que se refere à assistência estudantil, na década de 1970 é criado, pelo Governo Federal, o Departamento de Assistência Estudantil (DAE), vinculado ao Ministério da Educação (MEC), com o objetivo de manter uma política de assistência estudantil para graduandos em nível nacional, dando prioridade aos programas de alimentação, moradia e assistência médico-odontológica, conforme destaca Dumaresq (2014).

A expansão da educação superior nas últimas décadas ocorre a partir de três necessidades do capital
No cenário contemporâneo, marcado pela reestruturação econômica, política e ideológica do capital, em resposta à crise estrutural que se inicia nos anos 1970, a educação, assim como outros direitos sociais, é transformada em um lucrativo negócio, tendo em vista a busca capitalista por novos campos de valorização. Segundo Lima (2013, p. 11-12), a expansão da educação superior nas últimas décadas ocorre a partir de três necessidades do capital, quais sejam: subordinar a ciência à lógica do mercado, constituir novos campos de lucratividade e construir "estratégias de obtenção de consenso em torno do projeto burguês de sociabilidade em tempos de neoliberalismo reformado".

Nesse sentido, observa-se o papel ativo do Estado na reconfiguração da política educacional brasileira sob a lógica do mercado, por meio de mecanismos como: acordos com os organismos internacionais do capital; autorização e credenciamento das IES privadas; legalização da privatização interna das IES públicas (que passam a vender serviços educacionais, como cursos de pós-graduação lato sensu e mestrados profissionalizantes); financiamento público indireto para o setor privado, via Programa de Financiamento Estudantil (Fies) e Programa Universidade para Todos (Prouni); certificação em larga escala e massificação da formação profissional, 
por meio de ações como o ensino a distância (EAD) e o Programa de Apoio a Planos de Reestruturação e Expansão das Universidades Federais (Reuni); além de incentivo à competitividade e ao produtivismo, que condicionam a política de pesquisa e de pós-graduação, e da intensificação do trabalho docente (LIMA, 2013).

Nesse contexto, a Associação Nacional dos Dirigentes de Instituições Federais de Ensino Superior (Andifes) pauta a questão do acesso e da permanência dos estudantes no ensino superior e, em 1987, é criado o Fórum Nacional de Pró-Reitores de Assuntos Comunitários e Estudantis (Fonaprace), com o objetivo de fortalecer as políticas de assistência estudantil e democratizar o acesso para jovens de baixa renda.

No governo de Fernando Henrique Cardoso - FHC (1995-2002), marcado por medidas de ajustes estruturais e fiscais orientadas para o mercado, é criado o atual Conselho Nacional de Educação (CNE), órgão que passa a assumir funções deliberativas, facilitando os processos de autorização, reconhecimento e credenciamento de cursos e instituições do setor privado, e delegando maiores responsabilidades ao setor privado para a expansão do ensino superior (FERREIRA, 2012).

A LDB/1996, constituída em um momento de embates políticos entre as forças em defesa da educação pública e as forças conservadoras que tensionam para que a reforma da educação seja consentida sob os moldes da reforma do Estado, acaba por materializar as propostas conservadoras, estabelecendo novas diretrizes para a educação, mediante as orientações de organismos internacionais, como o Fundo Monetário Internacional (FMI) e a Organização Mundial do Comércio (OMC), entre as quais se destacam: a redução da participação do Estado como organizador e financiador da educação; a diversificação das IES ${ }^{5}$ e a diferenciação das modalidades de ensino; a política de resultados destinada às IES públicas a partir da eficiência e da eficácia; e a flexibilização dos processos de abertura de cursos alternativos com baixo custo, por exemplo, os cursos a distância.

O governo de Lula da Silva (2003-2010) é marcado pela expansão da educação superior a partir de um arcabouço jurídico (Medidas Provisórias, Projetos de Lei, Leis, Decretos) ${ }^{6}$, que intensifica a reformulação do ensino superior como parte da contrarreforma do Estado, revelando um novo ciclo de disseminação das medidas neoliberais (LIMA, 2013). Observa-se, todavia, que o governo Lula, embora dê continuidade ao projeto de expansão da educação superior por via do mercado, adota medidas favoráveis à expansão do ensino superior público, com a criação de 14 novas universidades federais e a ampliação da rede federal de educação tecnológica e profissional. O Decreto n. 5.224/2004 regulamenta a organização dos Centros Federais de Educação Tecnológica (CEFET), que passam a ofertar cursos de nível técnico, tecnológico e de formação inicial e continuada para trabalhadores.

A proposta de expansão do ensino profissionalizante da rede federal se materializa com a transformação dos CEFET em Institutos Federais de Educação, Ciência e Tecnologia, mediante o Decreto n. 6.095/2007. O objetivo principal é unificar as 
instituições da rede federal de educação profissional e tecnológica de um mesmo estado ou microrregião. Após intensos debates para análise da proposta do referido decreto, é instituída a Rede Federal de Educação Profissional, Científica e Tecnológica, por meio da Lei n. 11.892/2008, que cria os IF (SOUSA; LIMA; OLIVEIRA, 2011), com a finalidade de integração da educação básica à educação profissional e à superior, por meio da otimização da infraestrutura física, dos quadros de pessoal e dos recursos de gestão.

0 CEFET-CE é reconhecido pelo MEC como instituto

de ensino superior de graduação e pós-graduação
Outra medida que marca o governo Lula é a aprovação da Portaria Normativa n. 39, de 2007, que institui o Programa Nacional de Assistência Estudantil (PNAES) e explicita as ações a serem desenvolvidas no âmbito das instituições de ensino superior públicas referentes à assistência estudantil. Posteriormente, é aprovado o Decreto-lei n. 7.239/2010, que ratifica o PNAES, bem como seus objetivos, ações, público prioritário, responsabilidades das instituições federais na execução do programa e o repasse de recursos (BRASIL, 2010). No ano de 2012, são aprovadas, por meio da Lei n. 12.711, as cotas sociais e raciais, posteriormente regulamentadas, conforme a Portaria normativa n. 18 do MEC, que reserva $50 \%$ das vagas para candidatos que se autodeclaram negros, pardos, indígenas, oriundos de famílias de baixa renda e que cursaram integralmente o ensino médio na rede pública de ensino.

O governo de Dilma Rousseff (2011-2016) dá continuidade ao programa de expansão da educação superior desenvolvido pelo governo Lula, com a construção de quatro novas universidades federais, a criação de 47 novos campi universitários e 208 novos Institutos Federais por todo o Brasil. Desse modo, as políticas assumidas pelos governos Lula e Dilma para a educação superior parecem seguir a perspectiva da equidade social associada ao desenvolvimento econômico, por meio da capacitação de mão de obra para promover a empregabilidade da população, especialmente com a expansão das instituições federais de educação superior.

\section{A assistência estudantil nos Institutos Federais do Ceará: particularidades do campus Crateús}

A partir dos anos 2000, com a política de expansão da educação superior, os Institutos Federais do estado do Ceará passam a ser ampliados. No ano de 2004, por meio do Decreto n. 5.225/2004, o CEFET-CE é reconhecido pelo MEC como instituto de ensino superior de graduação e pós-graduação, incluindo os cursos de formação de professores e tecnólogos. No ano de 2008, os Centros são transformados em Institutos Federais de Educação, Ciência e Tecnologia (IFCE). Essa transformação altera a dinâmica das instituições e realiza a fusão do CEFET campus Fortaleza, as Escolas Agrotécnicas Federais de Crato e Iguatu e os Institutos das cidades 
de Juazeiro do Norte e Cedro. A unificação dos Institutos e das Escolas Técnicas confere um novo perfil às instituições, que passam a ter o caráter de autarquias federais do Poder Executivo e a ser vinculadas ao MEC, de acordo com a Lei $n$. 11.892/2008. A partir de então, o IFCE passa a ser uma instituição de educação profissional equiparada à universidade que desenvolve cursos técnicos de nível médio (50\% das vagas ofertadas), cursos de licenciatura e bacharelado (com 20\% das vagas), cursos de tecnologia, pós-graduação, realização de pesquisa e extensão.

0 processo de interiorização dos

IF aumentou a demanda potencial por assistência estudantil
Seguindo o percurso de ampliação das universidades públicas, a Rede Federal de Educação Profissional e Tecnológica (EPT), da qual faz parte o Instituto IFCE-CE, também passa a ser inserida no contexto da expansão da educação superior, guiada por vários propósitos. A estratégia principal é a ampliação da política de educação profissional como um dos mecanismos que visam alavancar o crescimento e o desenvolvimento de determinadas regiões, tanto com a formação em áreas técnicas e profissionais como para o avanço nos setores econômicos específicos de cada região.

Para materializar essa estratégia, há a interiorização dos IF, com a construção de novos campi, proporcionando o aumento do número de vagas, implantando cursos técnicos superiores e alterando a infraestrutura das IES. O objetivo do processo de interiorização dos Institutos Federais é instalar campi em regiões com maior carência socioeconômica e educacional (DUMARESQ, 2014). No Estado do Ceará, no ano de 2005, havia 3 (três) campi instalados em todo o estado; no ano de 2016, a quantidade de campi funcionando aumentou para 27, espalhados em várias regiões do Estado.

O processo de interiorização dos IF aumentou a demanda potencial por assistência estudantil. O público de jovens que ingressa nos IF é bastante heterogêneo, pois as instituições oferecem cursos em diferentes níveis e modalidades de ensino, o que passa a requerer ações efetivas, as quais garantam não só que os estudantes ingressem, mas possam permanecer no curso até a sua conclusão.

Segundo Menezes (2012), o debate sobre acesso e permanência no ensino superior se intensifica quando entra na agenda das discussões a inclusão dos segmentos sociais historicamente aviltados do direito à educação. Com relação ao acesso, destacam-se as principais barreiras que dificultam o ingresso de jovens pobres nas universidades públicas, por exemplo, a extrema seletividade dos vestibulares tradicionais e as lacunas deixadas por um ensino médio de relativa qualidade. Essa realidade esconde outros determinantes, principalmente no momento da escolha do curso. A procura por cursos de menor prestígio social pode ser uma estratégia para o ingresso, já que são menos concorridos ou exigem notas mais baixas para o acesso. Tal escolha simboliza as reais condições socioeconômicas dos estudantes, os déficits de aprendizado deixados pelo ensino médio e, em alguns casos, a necessidade de conciliar trabalho e estudos. 
A ação dos movimentos sociais em torno da democratização do ensino superior e a inclusão da pauta por políticas de acesso e permanência foram fundamentais para a aprovação de legislações que garantam aos grupos subalternizados o direito à educação gratuita, de qualidade e democrática, em uma sociedade na qual os padrões da organização social deram origem a múltiplas faces da desigualdade (MENEZES, 2012). Atualmente, o Programa Nacional de Assistência Estudantil (PNAES) é o principal instrumento que consubstancia os mecanismos de efetivação de ações e programas que auxiliam a permanência dos estudantes no ensino superior até o término dos cursos de graduação.

A diversificação do público que passa a ter acesso à universidade resulta em importantes dados que explicitam a necessidade da efetivação do programa de assistência estudantil no âmbito acadêmico, e culminam, com base em estudos realizados pelo Fonaprace e pela Andifes encaminhados ao Ministério da Educação (MEC), na elaboração do PNAES, mediante a Portaria Ministerial n. 39/2007, que traz objetivos, diretrizes e definições para ações e projetos de assistência estudantil.

Posteriormente, com a aprovação do Decreto n. 7.234/2010, o PNAES é instituído e passa a ter como objetivos precípuos: democratizar o acesso e a garantia de condições de permanência dos jovens no ensino superior; reduzir os efeitos das desigualdades sociais e regionais na permanência e conclusão de cursos de nível superior; diminuir as taxas de evasão e retenção; contribuir para a promoção da inclusão social na educação (DUMARESQ, 2014).

Com relação aos pressupostos que norteiam o PNAES, destaca-se o desenvolvimento de mecanismos e estratégias que possibilitem a permanência dos graduandos em situação de vulnerabilidade ${ }^{7}$ social e econômica até a conclusão do curso. A implantação do Programa conduz à ampliação das ações que materializam a assistência estudantil, dentre as quais: moradia estudantil; transporte; atenção à saúde; inclusão digital; cultura; esporte; creche; apoio pedagógico; inclusão pela via do acesso, do estímulo à participação e à aprendizagem de estudantes com deficiência, transtornos globais do desenvolvimento e altas habilidades, e superdotados (BRASIL, 2010).

Nesse sentido, Menezes (2012) ressalta que, embora a assistência estudantil ainda não seja uma política consolidada, o PNAES é um importante instrumento de reconhecimento de direitos, com caráter de inclusão, por meio de ações de permanência que pretendem apoiar a democratização do acesso.

A constituição da assistência estudantil nos Institutos Federais tem como base o Plano Nacional de Assistência Estudantil (2007), o PNAES (2010) e o próprio regulamento da instituição, que norteia o processo de seleção e acompanhamento da concessão dos auxílios e bolsas aos estudantes. O Plano de Desenvolvimento Institucional (PDI) 2014-2018 apresenta as ações da assistência estudantil que são desempenhadas junto aos discentes para propiciar a permanência destes, destacando-se: o atendimento social e psicológico aos estudantes; a concessão de au- 
xílios em forma de pecúnia; e a articulação das ações ao ensino, à pesquisa e à extensão. O público-alvo são os estudantes que cursaram o ensino básico na rede pública e/ou que possuem renda familiar per capita de até um salário mínimo e meio. O processo de seleção para a concessão dos auxílios prioriza, sobretudo, a situação socioeconômica da família do jovem, como está determinado no artigo $5^{\circ}$ do Regulamento da Política de Assistência Estudantil (RAE) do IFCE, aprovado em 2015, a saber: "realizar mapeamento da realidade socioeconômica e acadêmica de cada estudante atendido pela política a fim de direcionar suas ações" (INSTITUTO FEDERAL DE EDUCAÇÃO, CIÊNCIA E TECNOLOGIA DO CEARÁ, 2015).

\section{0 processo de seleção}

\section{para a concessão}

dos auxílios prioriza,

sobretudo, a

situação

socioeconômica da

família do jovem
No campus do IFCE Crateús, o PNAES é desenvolvido por meio da Coordenação de Assuntos Estudantis (CAE), composta por uma equipe multidisciplinar constituída por profissionais das áreas de Serviço Social, Psicologia, Enfermagem, Odontologia e Nutrição, além de assistentes de alunos ${ }^{8}$. Com relação ao acesso para os cursos superiores, este se dá pelo Sistema de Seleção Unificada (SISU); já nos casos de transferidos e graduados, o campus realiza processos seletivos periodicamente, sendo a divulgação por meio de editais disponíveis no sítio eletrônico da instituição. O IFCE reserva 50\% das vagas para alunos egressos de escolas públicas e para alunos que declararem pertença étnica e renda familiar de até um salário mínimo.

De acordo com o PDI do IFCE, a assistência estudantil nos IFES é um direito que tem como finalidade reduzir as taxas de evasão e retenção, bem como democratizar o ensino, promovendo inclusão social por meio da educação. Os auxílios que são disponibilizados em forma de pecúnia constituem as principais estratégias para a permanência dos estudantes no curso até a conclusão. No IFCE Crateús, os auxílios concedidos ${ }^{9}$ são: auxílio-moradia, alimentação, transporte (estes três em forma de valores pecuniários mensais), auxílio-óculos, além de viagens e visitas técnicas e o auxílio acadêmico, sendo que estes dois últimos independem da renda do estudante.

\section{A trajetória e os significados da assistência estudantil para os jovens estudantes dos cursos superiores do IFCE Crateús}

Segundo Pimenta (2001), para o jovem estudante, a formação universitária e a preparação profissional não significam apenas um ritual de passagem para a vida adulta, mas a elaboração de um projeto para si, que envolve a construção de uma imagem futura de si, com a articulação dos meios apropriados para a consolidação e a efetivação do seu projeto, do seu sonho de vida.

Os interlocutores da pesquisa ora apresentada são alunos dos cursos superiores do IFCE campus Crateús beneficiários do programa de assistência estudantil da 
instituição. De acordo com documentos fornecidos pela CAE, no primeiro semestre de 2016, foram concedidos 19 auxílios-moradia para estudantes dos cursos superiores que residem em localidades distantes de Crateús e necessitam do auxílio para custear o aluguel. Dentre os alunos beneficiários: 8 residem na zona rural de Crateús e 11 nos municípios circunvizinhos. A maioria das famílias desses alunos mora em residência própria, no total de 12, sendo que cinco famílias moram em casa alugada e duas em imóveis cedidos. Em relação à renda do grupo familiar, oito famílias recebem até 1 salário mínimo; 10, entre 1 e 2 salários mínimos; e apenas uma família tem renda de 3 salários mínimos.

Com relação ao auxílio-transporte, foi concedido para 19 alunos, dos quais três são oriundos da zona rural de Crateús e 16, dos municípios circunvizinhos. Em relação às condições de moradia das famílias desses alunos, todas residem em domicílio próprio. A renda do grupo familiar de quatro dessas famílias é de até 1 salário mínimo; 12 recebem entre 1 a 2 salários mínimos e apenas três famílias ganham até 3 três salários mínimos.

\section{A ocupação que predomina entre os pais dos alunos é o trabalho na agricultura e na construção civil}

Destaca-se que no processo seletivo para a concessão de auxílios, os alunos podem realizar inscrições para todas as modalidades disponíveis, desde que atendam às exigências especificadas no edital de seleção e apresentem a documentação exigida. No entanto, de acordo com os objetivos estabelecidos pelo RAE, no caso do auxílio-moradia, é voltado para subsidiar despesas com habitação e se destina aos discentes com referência familiar e residência domiciliar fora da sede do município onde está instalado o campus, sem haver condições de se locomoverem diariamente; no caso do auxílio-transporte, é destinado para subsidiar a locomoção diária dos discentes no trajeto residência/campus/residência durante os dias letivos.

De acordo com o perfil socioeconômico traçado pela equipe de profissionais da CAE, das 38 famílias dos discentes beneficiários do programa de assistência estudantil do campus (com o auxílio-moradia e transporte), 12 estão inscritas no Cadastro Único do Governo Federal, sendo que apenas oito recebem o benefício do Programa Bolsa Família. A ocupação que predomina entre os pais dos alunos é o trabalho na agricultura e na construção civil. Todos os alunos beneficiários realizaram o ensino fundamental e médio em escolas públicas, com exceção de um estudante que realizou em escolar particular, sendo contemplado com bolsa.

Para a entrevista, foram selecionados oito alunos dos cursos superiores, entre os quais: três alunos de Zootecnia, dois de Matemática, dois de Letras, e um de Física. A escolha dos alunos aconteceu mediante a disponibilidade dos interlocutores. Todos os alunos entrevistados são oriundos da zona rural da microrregião do Sertão de Crateús. Entre eles, apenas um recebe auxílio-transporte, por conta da proximidade da localidade onde mora; os demais são oriundos de outras cidades e necessitaram morar em Crateús, recebendo auxílio-moradia. 
De acordo com o relato dos alunos, os cursos em que estão matriculados são, geralmente, sua segunda opção de formação. Eles sonhavam em realizar outra graduação, mas, devido à pontuação obtida no Exame Nacional do Ensino Médio (Enem), ingressaram em cursos com nota de corte mais baixa. No entanto, no momento da escolha do curso, o critério principal foi a afinidade e o gosto pela área, além das oportunidades de acesso ao mercado de trabalho. Outro aspecto destacado por todos é a localização da escola, que é acessível às cidades circunvizinhas, haja vista que os alunos entrevistados são todos oriundos de outras cidades. O relato a seguir expressa essa realidade:

Eu queria estudar na UFC e fazer Engenharia, a Matemática era a segunda opção. Como Crateús é perto, preferi ficar por aqui, pois moro em Nova Russas, aqui é perto de casa. [...] Mas também sempre tive vocação para ensinar, acabei ficando entre esses dois caminhos e acabei fazendo Matemática por aqui mesmo $(\text { SONHADORA })^{10}$.

É importante ressaltar que o acesso à educação superior, como assinalam Silva e Veloso (2013), compreende tanto a dimensão do ingresso, cujos principais indicadores são a quantidade de vagas ofertadas e as formas que assumem os processos de seleção, quanto a permanência e a qualidade da formação, que envolvem desde os programas de fixação do estudante à participação deste nas decisões acadêmicas. Nessa perspectiva, a garantia do acesso passa por uma série de aspectos condicionantes de tais dimensões, a começar pela escolha do curso e da carreira que se pretende seguir. Para aqueles que puderam contar com uma boa educação desde a infância, as possibilidades de optar pelas consideradas "carreiras de sucesso", geralmente mais concorridas, e de conseguir uma vaga nas melhores universidades são maiores, por exemplo, do que para aqueles que estudaram na rede pública de ensino, cujas possibilidades de manter-se na escola dependem, muitas vezes, da suficiência de vagas noturnas (PIMENTA, 2001).

Com relação à modalidade de ingresso, dos oito interlocutores, quatro ingressaram por meio do Enem em ampla concorrência e quatro mediante cotas raciais e sociais. Todos, no entanto, consideram de suma importância as ações afirmativas como estratégias que oportunizam o acesso de jovens negros, egressos de escolas públicas e de famílias de baixa renda ao ensino superior público, como revela um estudante entrevistado:

Ingressei pelo Enem, através das cotas. Se não tivesse as cotas, seria mais difícil para ingressar. Com relação às cotas, antes de entrar aqui, eu era contra, porque achava que todo mundo deveria ter direitos iguais, achava que todos tinham a mesma capacidade. Mas quando entrei, mudei de ideia. Sempre fui um aluno muito bom no ensino médio, sempre fui de escola pública, mas eu vi que colegas meus que estudavam em escolas particulares tinham mais vantagens, porque, de certa forma, eles tinham um conhecimento mais avançado, isso me igualou a eles, porque a 
mesma capacidade que eu tinha, eles tinham, mas não o mesmo saber, porque eles já tinham passado por fases mais avançadas do que eu (DETERMINAÇÃO).

Um dado importante a ser analisado é a qualidade do ensino médio público. Dos oito interlocutores, sete realizaram o ensino médio em escolas públicas e relatam a precarização do ensino e das instituições. O déficit de aprendizado é observado quando a maioria dos alunos diz não ter conseguido obter nota suficiente para ingressar nos cursos que gostariam de cursar, entre eles, cursos considerados mais frequentados pelos filhos da elite, como Direito e Engenharia Civil. As consequências da falta de um ensino médio de boa qualidade se expressam nas dificuldades enfrentadas no ensino superior, conforme assinala uma estudante entrevistada:

Quando cheguei aqui, encontrei muitas dificuldades, não tinha uma base suficiente, não estava preparada. Foi bem difícil no começo. Agora já estou mais adaptada. Não culpo os professores, porque foi uma série de determinações que atrapalhou o desenvolvimento do aprendizado, a estrutura da escola, alguns alunos, a direção, a desvalorização dos professores (CORAGEM).

Dias Sobrinho (2010) destaca diversas debilidades entre jovens pertencentes a camadas mais pobres da sociedade, desde aquelas relacionadas ao processo de ensino-aprendizagem na educação básica, até a falta ou insuficiência de informações sobre a realidade da vida universitária, o que acaba contribuindo para a exclusão desses jovens da educação superior e para sua baixa capacidade competitiva no mercado de trabalho. O autor chama atenção para o tipo de exclusão que não é explicitado nas estatísticas, isto é, a "exclusão por dentro do sistema, cujas faces são a oferta de ensino de baixa qualidade e a auto-exclusão", que os próprios jovens enfrentam (DIAS SOBRINHO, 2010, p. 1230).

Outro ponto que merece destaque é o estigma que os cursos considerados de baixo prestígio social carregam na sociedade. Um aluno do curso de Letras relata sua experiência: "Aqui em Crateús, não tem cursos como Medicina e Direito. Nesse mundo capitalista, são os mais valorizados. Já sofri preconceitos com relação ao curso que faço" (Comprometimento).

É nesse sentido que Menezes (2012) aponta a estreita relação do acesso aos cursos de elevado prestígio social com a origem socioeconômica do estudante. Determinados cursos têm o público essencialmente formado por estudantes oriundos das classes mais ricas, enquanto em outros ocorre o inverso, o que se reflete na intensa seletividade social na escolha das carreiras, nos significados e valores que são construídos em torno dessas escolhas, nas consequências para a vida do estudante e, posteriormente, para a carreira profissional.

Os alunos também destacam o significado de estudar no IFCE e a importância da instalação do campus para a região do Sertão de Crateús. Ressaltam, sobretudo, a ampliação de oportunidades para os jovens das camadas de baixa renda que moram na zona rural: 
O IF é uma grande oportunidade para todas as pessoas que moram aqui e aos arredores, que querem fazer o ensino superior e mudar de vida, e hoje em dia os jovens buscam muito a independência financeira, então acho que é uma oportunidade boa para quem quer ser independente, ajudar a família, ingressar no mercado de trabalho. Os cursos daqui procuraram atender as carências da região, pois é muito difícil você encontrar um professor formado em Matemática, Física. Se a pessoa quiser mesmo, no final do curso com certeza ela consegue ingressar no mercado de trabalho (SONHADORA).

No âmbito da educação superior, a assistência estudantil deve ser compreendida como um investimento em médio e longo prazos, em uma perspectiva de justiça social, uma vez que seus resultados podem ir além da redução dos índices de evasão e de retenção escolar, podendo ter reflexos na vida dos sujeitos e de suas famílias, que enfrentam inúmeras dificuldades. Ao garantir a permanência dos estudantes nos cursos de graduação até sua conclusão, contribui para que alcancem melhores oportunidades no mercado de trabalho, com possibilidades de ascensão social. O suporte socioeconômico aos estudantes das camadas pobres contribui, ainda, para o cumprimento da missão da universidade de socializar saberes, e auxilia a diminuição das desigualdades sociais, amenizando efeitos do pertencimento de classe (VARGAS, 2011).

A instalação do campus na região, segundo os alunos, possibilita a qualificação dos jovens para o ingresso no mercado de trabalho, principalmente na área da Educação, haja vista a grande carência de profissionais especializados na região.

Quanto à permanência, os alunos destacam a importância dos auxílios-moradia e transporte - geralmente os mais procurados pelos discentes - para a vida acadêmica e financeira. Relatam as dificuldades na rotina estudantil e de permanecer no curso sem os auxílios, que contribuem tanto no custeio das despesas quanto no rendimento acadêmico, pois assim os jovens não necessitam trabalhar para pagar o ônus de morar em outro município, considerando o pouco recurso que suas famílias disponibilizam para o investimento em sua formação, conforme revelam as falas a seguir:

Sem o auxílio, não daria para permanecer estudando. Acho que deveríamos passar por um acompanhamento psicológico, porque passamos por muitas dificuldades, sentimos vontade de desistir, porque estamos longe da família e temos que arcar com muitas responsabilidades, além da questão de você estudar para entrar no mercado de trabalho. Junta tudo isso, fica muito pesado (SONHADORA).

O auxílio é uma ajuda, pois minha mãe trabalha no campo, então ela tem que custear minhas despesas aqui e manter a casa dela. Muito difícil manter duas casas com água, luz, alimentação, e muitas vezes temos que abdicar de possuir outros itens, como roupas, calçados bons, são escolhas que futuramente teremos o resultado. O auxílio é fundamental (DEDICAÇÃO). 
Os alunos apontam como ponto negativo da assistência estudantil no Instituto a renovação anual da concessão dos auxílios e afirmam que estes deveriam ser garantidos durante toda a graduação, sem terem que passar pelos trâmites burocráticos de novas seleções. No entanto, ao serem indagados sobre o processo de seleção para os auxílios, citam alguns pontos com os quais concordam, tais como: a visita domiciliar, que permite conhecer de perto a realidade do aluno e da família; e as reuniões que a CAE realiza para discutir a aplicabilidade do orçamento. Como principal desafio, apontam a ampliação dos recursos, de modo que possam atender a toda a demanda estudantil e garantam a um número maior de jovens o direito de permanecer no Instituto até a conclusão do curso.

Silva e Veloso (2013) destacam a seletividade como paradigma recorrente que reflete na definição de políticas de acesso. As autoras destacam que tanto a ideia da capacidade de cada um como a de classificação "revelam conteúdos ideológicos associados à atribuição individual de sucesso ou fracasso na vida escolar, tendendo a neutralizar ou a esconder as responsabilidades sociais implicadas na questão, como o papel do Estado perante os bens sociais" (SILVA; VELOSO, 2013, p. 734).

A realização do processo seletivo para a concessão dos auxílios estudantis acontece mediante a publicação de edital, disponível na página eletrônica do Instituto, com a realização das inscrições e anexação dos documentos no Sistema Informatizado de Assistência Estudantil do IFCE (Sisae) ${ }^{11}$. A seleção dos alunos beneficiários se dá por meio de análise documental, entrevistas e visitas domiciliares realizadas pelo serviço social da instituição.

Acerca do entendimento sobre o que seja assistência estudantil, os alunos definem como sendo um direito que garante a permanência em instituições de ensino superior públicas, para alunos oriundos de outras regiões, provenientes de famílias de baixa renda, que durante muito tempo tiveram poucas oportunidades de aquisição de conhecimentos e aprendizados. E apontam a importância de garantir o direito ao acesso a um ensino público gratuito e de qualidade.

Percebe-se, a partir das falas dos alunos, que, embora todos considerem a estrutura do campus excelente, ainda convivem com algumas limitações que interferem no desenvolvimento dos estudos e das atividades e afetam diretamente o rendimento acadêmico, por exemplo, o pouco acervo de livros da biblioteca e a falta de um restaurante universitário. Segundo eles:

O que falta é o RU [restaurante universitário], porque às vezes precisamos ficar o dia todo no campus, mas temos que ir comer em casa, e acabamos perdendo tempo (PERSEVERANÇA).

Falta o RU, deveria ter. É muito importante para reduzir os gastos dos alunos, têm alunos que ficam os dois períodos no campus e precisam sair para ir almoçar em casa, isso é muito ruim (DETERMINAÇÃO). 
Como pontos positivos de estudar no IFCE Crateús, os alunos destacam a boa infraestrutura do campus (salas de aula e laboratórios confortáveis, disponibilidade de salas de estudos individual e coletiva, acesso à internet etc.), as ações de assistência estudantil (como os auxílios, a distribuição de lanche para todos os alunos e o transporte escolar, que viabiliza a chegada até o campus, haja vista que a localização do Instituto fica em um dos extremos da cidade), a qualificação dos professores e as possibilidades de inserção no mercado de trabalho. Os relatos a seguir demonstram a satisfação dos alunos com a instituição de ensino em que estudam:

Não tenho do que reclamar. Passei minha vida escolar toda estudando sentado em uma cadeira desconfortável, lousa de giz. Aqui temos outra realidade, salas climatizadas, biblioteca com uma razoável quantidade de livros, embora precise aumentar o acervo de livros, a distribuição de lanche gratuito. [...] O IF é muito valorizando na região [...]. Desenvolvemos muitas pesquisas e os projetos de extensão são riquíssimos e bem-diversificados, todos os professores desenvolvem pesquisas (DEDICAÇÃO).

Considero o IF a melhor instituição de ensino superior da região. É muito bom, bem-estruturado. Aponto como vantagens, por exemplo, o transporte escolar, o lanche, coisas que em outras instituições não há. Destaco as bolsas de assistência estudantil para a permanência dos alunos. Também vai interferir na economia, por meio do mercado de trabalho com pessoas mais qualificadas; prepara mão de obra para a região (REALIZAÇÃO).

De fato, como destacam Andrade, Santos e Cavaignac (2016), a criação dos IF e sua interiorização são expressões da significativa expansão da educação superior como política pública durante o governo Lula (2003-2010), o qual deu continuidade às diretrizes do governo $\mathrm{FHC}$ no campo educacional, mas destacou-se por algumas iniciativas no sentido de equalizar o acesso ao ensino superior, em um contexto no qual a discussão não se restringe apenas ao ingresso, mas é ampliada para questões relacionadas à permanência, tendo em vista a necessidade de prover necessidades materiais e imateriais, sobretudo de estudantes pobres, por meio da assistência estudantil. As autoras assinalam, contudo, que, mesmo com a ampliação de garantias destinadas para um determinado número de estudantes em instituições de ensino superior como os IF, "não se pode perder de vista a perspectiva da universalidade quando se persegue a assistência estudantil como política pública de direito" (ANDRADE; SANTOS; CAVAIGNAC, 2006, p. 34).

\section{Considerações finais}

Este artigo teve como objetivo analisar o acesso dos jovens das classes populares ao ensino superior, a partir da expansão e interiorização da educação superior, por meio dos Institutos Federais. 
O que se apreende sobre o processo de expansão da educação superior é que ainda demanda a democratização do acesso à educação com qualidade. O ensino superior, seja em âmbito público, seja privado, tem o papel social de desenvolver de maneira integrada e interdisciplinar a formação profissional e a reflexão crítica sobre a sociedade, com produção de conhecimento e socialização de saber crítico em todas as áreas das atividades humanas.

Nesse sentido, destacam-se as pautas primordiais que historicamente o movimento estudantil, os docentes e os movimentos populares lutam para serem efetivadas, tais como: desenvolver pesquisa e extensão articuladas com as reais demandas do povo brasileiro, considerando e respeitando a diversidade e o pluralismo dos saberes e da cultura nacional; ampliar as políticas de assistência estudantil para atender aos filhos das classes populares; valorizar os direitos trabalhistas dos servidores e respeitar o trabalho dos docentes no âmbito acadêmico; e, sobretudo, guiar-se pela transparência em suas ações, no financiamento, e principalmente, com autonomia político-pedagógica.

Ao lado dos programas de incentivo à iniciativa privada e de financiamento estudantil, a interiorização das IES públicas, sobretudo dos Institutos Federais, surge como estratégia do Estado visando à expansão da oferta e à democratização do acesso à educação superior, principalmente pelos segmentos sociais que não têm condições de pagar por serviços educacionais. Tal iniciativa requer não somente mudanças nas formas de ingresso, mas também a promoção de condições efetivas de permanência dos estudantes nas IES públicas até a conclusão dos cursos.

Desse modo, o Programa de Assistência Estudantil se apresenta como importante mecanismo para que estudantes pobres tenham acesso ao ensino superior público e a oportunidade de mobilidade social dentro da estratificada sociedade brasileira.

Nesse cenário, apesar das limitações, compreende-se a interiorização dos Institutos Federais como um avanço que possibilita o acesso à educação pública, gratuita e de qualidade a jovens pobres e de regiões distantes. Essa ampliação muda o perfil social dos alunos que ingressam nos IF e gera demanda para a constituição de políticas que atendam às reais necessidades dos estudantes das camadas populares que ingressam na academia.

Cabe ressaltar que a constituição de políticas afirmativas, como a política de cotas, é fundamental para a garantia do ingresso das classes desfavorecidas ao ensino superior, no entanto, o acesso não se restringe ao ingresso, mas se expressa também nas condições de permanência dos estudantes nos cursos em que estão matriculados, cuja garantia se faz necessária como política efetiva de assistência estudantil.

É nesse sentido que a assistência estudantil, no cenário de ampliação da educação superior, é um mecanismo capaz de auxiliar tanto a formação profissional de qualidade como a diminuição das assimetrias sociais, ao garantir condições de permanência a estudantes pertencentes às camadas mais pobres que, com a 
conclusão do curso, poderão ter maiores oportunidades no mercado de trabalho e, consequentemente, de ascensão social, embora um diploma não seja garantia de emprego em uma sociedade marcada pelo desemprego estrutural.

Com relação à percepção dos alunos beneficiados, a respeito do programa de assistência estudantil, consideram que é necessário o aumento dos recursos para ampliação dos auxílios, e contratação de mais profissionais que possam atender toda a demanda. No entanto, consideram os auxílios em forma de pecúnia fundamental para a permanência no Instituto até a conclusão do curso, proporcionando condições para o desempenho acadêmico e mais qualidade de vida aos estudantes.

O caminho de desenvolvimento da assistência estudantil é perpassado por complexas contradições. Por um lado, é reconhecida a importante institucionalização desses programas para o avanço da educação como direito fundamental, indivisível e universal; por outro lado, paradoxalmente, a implementação é acompanhada de condicionalidades e seletividade do direito ao programa. Portanto, a materialização da assistência estudantil requer a transposição de barreiras e limites, para efetivamente consolidar e ampliar o direito à educação superior.

\section{Notas}

${ }^{1}$ A construção do campus ocorreu no ano de 2008, sendo que passou a funcionar apenas no ano de 2011. A estrutura física é composta por blocos administrativos, 10 salas de aula, auditório, biblioteca, ginásio, refeitório, parque aquático e laboratórios com acesso à internet. Atualmente, o campus passa por reformas, com a construção de novos blocos de ensino. A instituição oferta cursos de ensino técnico, tecnológico, bacharelado e licenciatura, e pós-graduação nas modalidades lato sensu e stricto sensu, com especializações e mestrados. Informações disponíveis no sítio do IFCE <http:// ifce.edu.br/>. Acesso em: 2 abr. 2016.

${ }^{2}$ A Universidade do Rio de Janeiro (URJ) é a primeira instituição de caráter universitário criada legalmente pelo Governo Federal, por meio do Decreto n. 14.343/1920, no governo do Presidente Epitácio Pessoa (FÁVERO, 2006).

${ }^{3}$ A primeira LDB, Lei n. 4.624/1961, estabelece, em seu artigo 90, a promoção dos serviços de assistência social, médico-odontológicos e de enfermagem aos alunos de todo o sistema de ensino. No artigo 91, explicita o desenvolvimento da assistência social, por meio do tratamento de casos individuais, com o uso de técnicas de grupo e organização social de comunidade (KOWALSKI, 2012).

${ }^{4}$ Nas décadas de 1940, 1950 e 1960, com o processo de desenvolvimento e a consolidação da indústria, várias instituições são criadas, entre as quais o Instituto Tecnológico de Aeronáutica (ITA), no ano de 1947; bem como o Conselho Nacional de Desenvolvimento Científico e Tecnológico (CNPq) e a Coordenação de Aperfeiçoamento de Pessoal de Nível Superior (Capes), ambos criados em 1951 (MINTO, 2011).

${ }^{5}$ O Decreto n. 2.306/1997 estabelece a distinção entre IES públicas, IES privadas sem fins lucrativos e IES privadas com fins lucrativos. O processo de diversificação das IES muda a organização acadêmica para universidades, centros universitários, faculdades integradas, faculdades, institutos superiores ou escolas superiores, conforme o art. $4^{\circ}$ do decreto supracitado (FERREIRA, 2012).

${ }^{6}$ Ressaltam-se algumas das prioridades que são pauta da ação política do governo Lula da Silva, a saber: a Lei n. 10.861/2004, que institui o Sistema Nacional de Avaliação da Educação Superior (Sinaes); a Medida Provisória n. 213/2004, que institui o PROUNI, pelo qual o governo concede isenção fiscal para que grupos empresariais ofertem educação superior para segmentos sociais 
alijados desse direito; os Decretos n. 5.800/2006 e n. 5.622/2005, que tratam da regulamentação do EAD e da criação da Universidade Aberta do Brasil (UAB), consórcio de instituições para oferta de cursos a distância; e o Decreto n. 6.096/2007, que institui o Reuni (LIMA, 2013).

${ }^{7}$ A Política Nacional de Assistência Social (PNAS/2004) caracteriza vulnerabilidades e riscos sociais como a situação de fragilidades e contingências que o(a) cidadão(ã) e sua família enfrentam na trajetória de seu ciclo de vida, por decorrência de imposições sociais, econômicas, políticas e de ofensas à dignidade humana. Disponível em: <http://www.mds.gov.br/webarquivos/publicacao/ assistencia_social/Normativas/PNAS2004.pdf>. Acesso em: 28 nov. 2016.

${ }^{8} \mathrm{O}$ assistente de aluno é o profissional que acompanha mais de perto a sua rotina e realiza o encaminhamento das demandas para os demais membros da equipe, de acordo com a necessidade de cada discente. Assume o cargo mediante concurso público. O nível de escolaridade exigido é o ensino médio completo.

${ }^{9}$ O subsídio se define da seguinte forma: Auxílio-moradia: despesas com habitação, como locação de imóveis, e se destina aos discentes com referência familiar e residência domiciliar fora da sede do município onde está instalado o campus; auxílio-alimentação: destina-se às despesas dos discentes para subsidiar alimentação durante os dias letivos; auxílio-transporte: locomoção diária dos discentes no trajeto residência/campus/residência, durante os dias letivos; auxílio-óculos: aquisição de óculos ou lentes corretivas e destina-se aos discentes com deficiências oculares; auxílio-acadêmico: contribui com as despesas de alimentação, hospedagem, passagem e inscrição dos discentes na participação em eventos que possibilitem o processo de ensino-aprendizagem, tais como eventos científicos, entre outros; auxílio-visitas e viagens técnicas: alimentação e/ou hospedagem, em visitas e viagens técnicas, programadas pelos docentes dos cursos, e expressas no plano de trabalho anual, de acordo com o Programa de Unidade Didática (PUD) de cada disciplina; auxílio didático-pedagógico: destina-se à aquisição de material, de uso individual e intransferível, indispensável para o processo de aprendizagem de determinada disciplina; auxílio-discentes mães/ pais: despesas com filho(s) de até seis anos de idade ou com deficiência, sob guarda do estudante pai ou mãe; auxílio-formação: ampliação da formação dos discentes, devendo as atividades (de ensino, pesquisa e extensão) estarem vinculadas ao curso no qual o aluno está matriculado; auxílio Proeja: para o deslocamento e as despesas dos alunos da modalidade de ensino jovens e adultos (INSTITUTO FEDERAL DE EDUCAÇÃO, CIÊNCIA E TECNOLOGIA DO CEARÁ, 2014).

${ }^{10}$ A escolha dos nomes fictícios dos interlocutores são expressões que trazem um significado forte nas falas dos alunos e representam, resumidamente, a trajetória estudantil de cada jovem.

${ }^{11}$ Disponível em: <http://ifce.edu.br/crateus/noticias/inscricoes-abertas-para-auxilios-estudantis-emcrateus.>. Acesso em: 21 nov. 2016.

\section{Referências}

ANDRADE, Francisca Rejane Bezerra; SANTOS, Geórgia Patrícia Guimarães dos; CAVAIGNAC, Mônica Duarte. Ingresso e permanência no ensino superior: a assistência estudantil em debate. In: ANDRADE, Francisca Rejane Bezerra; SANTOS, Geórgia Patrícia Guimarães dos; CAVAIGNAC, Mônica Duarte (Org.). Educação em debate: reflexões sobre ensino superior, educação profissional e assistência estudantil. Fortaleza: EdUECE, 2016.

\footnotetext{
ASSOCIAÇÃO NACIONAL DOS DIRIGENTES DE INSTITUIÇÕES FEDERAIS DE ENSINO SUPERIOR. Educação impõe virada de página. Brasília, DF, 19 jan. 2012. Disponível em: <http://www.andifes.org.br/educacao-impoe-virada-de-pagina/>. Acesso em: 30 maio 2016.
} 
ASSOCIAÇÃO NACIONAL DOS DIRIGENTES DE INSTITUIÇÕES FEDERAIS DE ENSINO SUPERIOR. Universia Brasil realiza seminário Evasão no Ensino Superior Brasileiro. Brasília, DF, 18 maio 2015. Disponível em: <http://www.andifes.org. br/universia-brasil-seminario-evasao-no-ensino-superior-brasileiro-recebeinscricoes/>. Acesso em: 28 maio 2016.

ASSOCIAÇÃO NACIONAL DOS DIRIGENTES DE INSTITUIÇÕES FEDERAIS DE ENSINO SUPERIOR. 0 drama das universidades brasileiras. Brasília, DF, 14 mar. 2016. Disponível em: <http://www.andifes.org.br/o-drama-das-universidadesbrasileiras/>. Acesso em: 28 maio 2016.

BOURDIE, Pierre. A "juventude” é apenas uma palavra. In: BOURDIE, Pierre. Questões de sociologia. Rio de Janeiro: Marco Zero, 1983. p. 112-121.

BRASIL. Constituição (1946). Constituição dos Estados Unidos do Brasil (de 18 de setembro de 1946). Brasília, DF: Presidência da República, [20--]. Publicado no DOU em 19 set. 1946. Disponível em: <http://www.planalto.gov.br/ ccivil_03/Constituicao/Constituicao46.htm>. Acesso em: 11 out. 2016.

BRASIL. Constituição (1988). Constituição da República Federativa do Brasil de 1988. 35. ed. Brasília, DF: Câmara dos Deputados, 2012.

BRASIL. Lei n. 4.024, de 20 de dezembro de 1961. Fixa as diretrizes e bases da educação nacional. [S.I.: Unesp, 2006?]. Reprodução digital da lei. Disponível em: <http://wwwp.fc.unesp.br/ lizanata/LDB\%204024-61.pdf.>. Acesso em: 27 nov. 2016.

BRASIL. Lei n. 9.394, de 20 de dezembro de 1996. Estabelece as diretrizes e bases da educação nacional. Diário Oficial da União, Brasília, DF, 23 dez. 1996. Disponível em: <http://portal.mec.gov.br/arquivos/pdf/ldb.pdf>. Acesso em: 18 ago. 2015.

BRASIL. Lei n. 11.892, de 29 de dezembro de 2008. Institui a Rede Federal de Educação Profissional, Científica e Tecnológica, cria os Institutos Federais de Educação, Ciência e Tecnologia, e dá outras providências. Diário Oficial da União, Brasília, DF, 30 dez. 2008. Disponível em: <http://www.planalto.gov.br/ccivil_03/_ ato2007-2010/2008/lei/l11892.htm>. Acesso em: 20 maio 2016.

BRASIL. Lei n. 7.234, de 19 de julho de 2010. Dispõe sobre o Programa Nacional de Assistência Estudantil. Natal: Instituto Federal de Educação, Ciência e Tecnologia do Rio Grande do Norte, [2010?]. Disponível em: <http://portal.ifrn.edu. br/institucional/planejamento/arquivos/decreto-no-7-234-2010-dispoe-sobre-oprograma-nacional-de-assistencia-estudantil-pnaes/view>. Acesso em: 8 jun. 2016. 
DIAS SOBRINHO, José. Democratização, qualidade e crise da educação superior: faces da exclusão e limites da inclusão. Educação e Sociedade, Campinas, v. 13, n. 113, p. 1223-1245, out./dez. 2010.

DUMARESQ, Zandra Maria Ribeiro Mendes. Análise da Política de Assistência Estudantil no âmbito do Instituto Federal do Ceará - campus de Fortaleza - sob o olhar dos discentes. 2014. Dissertação (Mestrado Profissional em Políticas Públicas e Gestão da Educação Superior) - Universidade Federal do Ceará, Fortaleza, 2014

FÁVERO, Maria de Lourdes de Albuquerque. A universidade no Brasil: das origens à reforma universitária de 1968. Educar, Curitiba, n. 28, p. 17-36, 2006. Disponível em: <http://www.scielo.br/pdf/er/n28/a03n28>. Acesso em: 16 maio 2016.

FERREIRA, Suely. Reformas na educação superior: de FHC a Dilma Rousseff (1995-2011). Linhas Críticas, Brasília, DF, n. 36, p. 455-472, maio/ago. 2012.

IAMAMOTO, Marilda Vilela; CARVALHO, Raul de. Relações sociais e serviço social no Brasil: esboço de uma interpretação histórico-metodológica. 4. ed. São Paulo: Celats, 1985.

INSTITUTO FEDERAL DE EDUCAÇÃO, CIÊNCIA E TECNOLOGIA DO CEARÁ. Plano de desenvolvimento institucional 2014-2018: Instituto Federal do Ceará. Fortaleza, 2014.

INSTITUTO FEDERAL DE EDUCAÇÃO, CIÊNCIA E TECNOLOGIA DO CEARÁ. Regulamento da política de assistência estudantil do IFCe. Fortaleza, 2015. Disponível em: <http://ifce.edu.br/estudantes/assistencia-estudantil/arquivos/rae27-03-14.pdf>. Acesso em: 10 jul. 2016.

IPEA. Evolução do acesso de jovens no ensino superior no Brasil. Brasília, DF, 2014. Disponível em: <http://www.ipea.gov.br/portal>. Acesso em: 11 jun. 2016.

KOWALSKI, Aline Vieira. Os (des) caminhos da política de assistência estudantil e o desafio na garantia de direitos. 2012. Tese (Doutorado em Serviço Social) Faculdade de Serviço Social, PUC-RS, Porto Alegre, 2012.

LIMA, Kátia. Expansão da educação superior brasileira na primeira década do novo século, parte 1: política educacional. In: PEREIRA, Larissa Dahmer; ALMEIDA, Ney Luiz Teixeira de. Serviço social e educação. 2. ed. Rio de Janeiro: Lumen Juris, 2013. 
MENEZES, Simone Cazarim de. Assistência estudantil na educação superior pública: o programa de bolsas implementados pela Universidade do Rio de Janeiro. Rio de Janeiro, 2012. Dissertação (Mestrado em Serviço Social) Departamento de Serviço Social, Pontifícia Universidade Católica do Rio de Janeiro, 2012.

MINTO, Lalo Watanabe. A educação da "miséria": particularidade capitalista e educação superior no Brasil. 2011. Tese (Doutorado em Educação) - Programa de Pós-graduação em Educação, Faculdade de Educação da Universidade Estadual de Campinas, Unicamp, Campinas, 2011.

PIMENTA, Melissa de Mattos. Jovens em transição: um estudo sobre a transição para a vida adulta entre estudantes universitários em São Paulo. São Paulo, 2001. Dissertação (Mestrado em Sociologia) - Programa de Pós-Graduação de Sociologia, Faculdade de Filosofia, Letras e Ciências Humanas, Universidade de São Paulo, São Paulo, 2001.

SANTOS, Gabrielle dos; FREITAS, Leana Oliveira. Ensino superior público brasileiro: acesso e permanência no contexto de expansão. Argumentum, Vitória, v. 6, n. 2, p. 182-200, jul./dez. 2014.

SILVA, Maria das Graças Martins da; VELOSO, Tereza Christina Mertens Aguiar. Acesso nas políticas da educação superior: dimensões e indicadores em questão. Avaliação, Sorocaba, v. 18, n. 3, p. 727-747, 2013.

SOUSA, Antonia de Abreu; LIMA, C. R. G.; OLIVEIRA, E. G. A política pública para a educação profissional e tecnológica no Brasil. Fortaleza: UFC, 2011.

VARGAS, Michely de Lima Ferreira. Ensino superior, assistência estudantil e mercado de trabalho: um estudo com egressos da UFMG. Avaliação, Campinas, v. 16, n. 1, p. 149-163, mar. 2011. 